OPEN ACCESS

Edited by:

Dirk Albert Balmer,

Syngenta, Switzerland

Reviewed by:

Karina van der Linde,

University of Regensburg, Germany

Juan Pablo Pardo,

National Autonomous University of

Mexico, Mexico

*Correspondence:

Florian Altegoer

altegoer@uni-marburg.de

Specialty section:

This article was submitted to

Plant Pathogen Interactions,

a section of the journal

Frontiers in Plant Science

Received: 19 February 2021

Accepted: 27 April 2021

Published: 21 May 2021

Citation:

Weiland $P$ and Altegoer F (2021) Identification and Characterization of

Two Transmembrane Proteins

Required for Virulence of

Ustilago maydis.

Front. Plant Sci. 12:669835.

doi: 10.3389/fpls.2021.669835

\section{Identification and Characterization of Two Transmembrane Proteins Required for Virulence of Ustilago maydis}

\author{
Paul Weiland ${ }^{1}$ and Florian Altegoer ${ }^{1,2 *}$ \\ 'Center for Synthetic Microbiology (SYNMIKRO), Faculty of Chemistry, Philipps-University Marburg, Marburg, Germany, \\ ${ }^{2}$ Department of Organismic Interactions, Max-Planck Institute for Terrestrial Microbiology, Marburg, Germany
}

Smut fungi comprise a large group of biotrophic phytopathogens infecting important crops such as wheat and corn. Through the secretion of effector proteins, the fungus actively suppresses plant immune reactions and modulates its host's metabolism. Consequently, how soluble effector proteins contribute to virulence is already characterized in a range of phytopathogens. However, membrane-associated virulence factors have been much less studied to date. Here, we investigated six transmembrane (TM) proteins that show elevated gene expression during biotrophic development of the maize pathogen Ustilago maydis. We show that two of the six proteins, named Vmp1 and Vmp2 (virulenceassociated membrane protein), are essential for the full virulence of U. maydis. The deletion of the corresponding genes leads to a substantial attenuation in the virulence of $U$. maydis. Furthermore, both are conserved in various related smuts and contain no domains of known function. Our biochemical analysis clearly shows that Vmp1 and Vmp2 are membrane-associated proteins, potentially localizing to the U. maydis plasma membrane. Mass photometry and light scattering suggest that Vmp1 mainly occurs as a monomer, while Vmp2 is dimeric. Notably, the large and partially unstructured C-terminal domain of $\mathrm{Vmp} 2$ is crucial for virulence while not contributing to dimerization. Taken together, we here provide an initial characterization of two membrane proteins as virulence factors of U. maydis.

Keywords: Ustilago maydis, membrane proteins, virulence, biotrophy, mass photometry, mistics

\section{INTRODUCTION}

An increasing number of infectious diseases are threatening agricultural and natural systems. This development results in large crop losses, with up to $20 \%$ of annual maize harvest loss caused by fungal pathogens such as Ustilago maydis (Fisher et al., 2012). Despite the high number of fungal species infecting plants, only a few fungal plant pathogen systems allow the physiological, molecular, and biochemical investigation of both host and parasite (Dean et al., 2012; Giraldo and Valent, 2013). Among those, the smut fungus U. maydis represents an excellent case to study the infection process. Smut fungi are a large group of biotrophic parasites with currently more than 1,500 described species infecting mostly grasses, including 
important cereal crops such as maize, wheat, barley, and sugar cane (Zuo et al., 2019). The host of $U$. maydis is the maize plant Zea mays and the wild ancestor teosinte ( $Z$. mays subsp. Mexicana), where it can infect all aerial parts of the plant and establishes a biotrophic interface with its host cells.

Biotrophy implies the formation of a tight interaction zone between host and fungal intruder that allows for the exchange of signals and nutrients without initiating apoptosis of host cell tissue. Biotrophic pathogens need to maintain their respective host's viability in order to complete their life cycle. Therefore, U. maydis suppresses defense responses, manipulates the metabolism of host cells, and alters their proliferation rate, ultimately leading to the formation of large spore-filled tumors in the infected tissue (Zuo et al., 2019). The secretion of a variety of effector proteins plays a critical role during this process (Lanver et al., 2017). Effector proteins can be grouped in apoplastic effectors, which remain in the apoplastic space between plant and fungal cells, and cytoplasmic effectors that are further translocated into the host cells' cytoplasm (Mueller et al., 2008).

This molecular warfare is not restricted to the apoplastic space or the cytosol of host cells. Instead, pathogenic development and tumor formation are accompanied by a thorough remodeling of both plant and fungal cell walls (Matei et al., 2018). These processes support fungal development as the breakdown and import of carbohydrates derived from the host are important sources of carbon for the fungus during growth (Sosso et al., 2019). Sugar sensing and its uptake have thus gained more attention in $U$. maydis in recent years, leading to the identification of several transporters essential for virulence (Wahl et al., 2010; Schuler et al., 2015). The genome of $U$. maydis encodes more than 19 sugar transporters, and most of them are upregulated during pathogenic development (Sosso et al., 2019). Consequently, plants have evolved mechanisms to detect and deplete apoplastic sugar concentrations to hinder fungal growth and activate immune responses (Lemoine et al., 2013; Morkunas and Ratajczak, 2014). While these examples are among the first transmembrane proteins studied in the infection context, they also highlight the relevance of membrane-embedded proteins during virulent growth of smut fungi.

However, there is little known on specialized membrane proteins involved in signaling, stimuli recognition, and thus establishing a compatible interaction with the respective host plants. In one case, the membrane protein Pit1, encoded within the protein important for tumors (pit) gene cluster, is required for tumor formation (Doehlemann et al., 2011). It has been reported to localize to hyphal tips, although the precise molecular function remains unclear.

Here, we have analyzed a set of six genes showing elevated expression levels during pathogenic development of $U$. maydis (Lanver et al., 2018) encoding proteins that harbor predicted transmembrane helices. Of those, two show a strong attenuation in virulence upon deletion of their respective genes (UMAG_00032 and UMAG_01689). Notably, deletion of one of the two genes (UMAG_01689) has already been shown to lead to a strong reduction in virulence (Uhse et al., 2018). We confirm the phenotype observed by Uhse and coworkers by using a different deletion approach and furthermore demonstrate that UMAG_01689 encodes a membrane protein. Accordingly, we name the two proteins Vmp1 and Vmp2 for virulence-associated membrane protein and present a biochemical characterization giving insights into their molecular architecture and suggesting a potential role during virulence of $U$. maydis.

\section{MATERIALS AND METHODS}

\section{Molecular Cloning of Expression Plasmids}

For the plasmid constructions, standard molecular cloning strategies and techniques were applied (Sambrook et al., 1989). All plasmids and primers used in this study are listed in Supplementary Tables S1, S2. For the overproduction of the C-terminal domain (CTD) of Vmp2, the plasmid pEMGB1$v m p 2_{\text {CTD }}$ was generated. The overproduced protein has been fused to the solubility-tag GB1 (56 amino acids), including a hexahistidine tag (Huth et al., 1997). To do so, the region encoding the $\mathrm{Vmp} 2_{\text {CTD }}$ was amplified by PCR from genomic DNA of U. maydis SG200 and inserted into the NcoI/XhoI sites of the vector pEMGB1. For the overproduction of the full-length constructs, the genes encoding Vmp1 and Vmp2 were amplified from genomic DNA of U. maydis SG200 without the signal peptide and subsequently ligated into the pEMstX1 vector using $B s a \mathrm{I}$ restriction sites. The protein constructs will be fused to a Mistics-tag (110 amino acids), including a hexahistidine tag (Roosild et al., 2005). In both plasmids, a tobacco etch virus (TEV) cleavage site is located between expression tag and cloned gene.

\section{Generation of $U$. maydis Gene Knockout Constructs}

The plasmid pMS73 was digested with Acc65I to integrate the respective sgRNA expression cassette via Gibson Assembly, according to Schuster et al. (2018). The PCR obtained a doublestranded DNA fragment containing the respective target sequences, scaffold, terminator, and the corresponding overlapping sequences. The fragments were cloned into pMS73 yielding pFA001 and pFA003-pFA007 (Supplementary Table S1). The target sequences (Supplementary Table S2) were designed using the E-CRISP tool (Heigwer et al., 2014). The inserts in all plasmids were validated by sequencing.

\section{Generation of $U$. maydis Complementation Constructs}

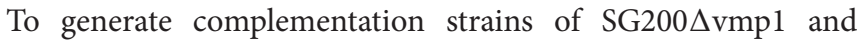
SG200 $\Delta$ vmp2, the constructs pFA511 and pFA512 were generated (Supplementary Table S1). Genomic DNA from U. maydis SG200 containing promoter and open reading frame (ORF) of the respective gene was amplified by PCR using the primers listed in Supplementary Table S2. The amplified fragments were introduced into the KpnI/NotI sites of plasmid p123 (Aichinger et al., 2003). Prior to transformation, the plasmids were linearized using the restriction enzyme SalI. 


\section{Strains, Growth Conditions, and Plant Infection Assays}

The Escherichia coli strain Dh5 $\alpha$ (New England Biolabs) was used for cloning purposes. The E. coli strain OverExpress ${ }^{\mathrm{TM}}$ C43 (DE3; Sigma-Aldrich) was used to express the full-length constructs of Vmp1 and Vmp2. The E. coli strain BL21 (DE3; Novagen) was used to express the CTD of Vmp2. E. coli strains were grown under constant shaking in a temperature-controlled incubator. Zea mays cv. Early Golden Bantam (EGB, Urban Farmer, Westfield, IN, United States) was used for infection assays with Ustilago maydis and grown in a temperaturecontrolled greenhouse (light and dark cycles of $14 \mathrm{~h}$ at $28^{\circ} \mathrm{C}$ and $10 \mathrm{~h}$ at $20^{\circ} \mathrm{C}$, respectively). U. maydis strains used in this study are listed in Supplementary Table S3. U. maydis strains were grown in $\mathrm{YEPS}_{\text {light }}$ medium [1\% (w/v) yeast extract, $0.4 \%$ $(\mathrm{w} / \mathrm{v})$ peptone and $0.4 \%(\mathrm{w} / \mathrm{v})$ sucrose] and subsequently adjusted to an $\mathrm{OD}_{600}$ of 1.0 using sterile double-distilled water. For the infection of maize plants, $500 \mu \mathrm{l}$ of $U$. maydis cultures were injected into the stem of 7 -day-old maize seedlings using a syringe as described by Kämper et al. (2006).

\section{Generation of $\boldsymbol{U}$. maydis Strains}

The genes encoding the six putative transmembrane proteins were disrupted in U. maydis SG200 using the CRISPR-Cas9 approach recently described for genetic manipulation of $U$. maydis (Schuster et al., 2016). A donor DNA was supplied during transformation to delete the respective ORF from the genome (Supplementary Figure S2). Isolated $U$. maydis transformants were confirmed for deletion of the respective genes by colony PCR using the primers listed in Supplementary Table S2 and sequencing (Supplementary Figure S2). To complement the phenotypes of SG200 $\Delta$ vmp1 and SG200 $\Delta$ vmp2, plasmids pFA511 and pFA512 were integrated into the ip locus of SG200. Isolated U. maydis transformants were confirmed by Southern-blot analysis to ensure single integration events in the ip locus (Keon et al., 1991).

\section{Production and Purification of Soluble Vmp2}

The CTD of Vmp2 was produced in Escherichia coli BL21 (DE3; Novagen). E. coli BL21 (DE3) was transformed with pFA508 to produce Vmp2 $2_{\text {СтD }}$ fused to an N-terminal GB1 tag including a hexahistidine tag. The protein production was performed in auto-inductive Luria-Miller broth (Roth) containing $1 \%(\mathrm{w} / \mathrm{v}) \alpha$-lactose (Roth). The cells were grown for $20 \mathrm{~h}$ at $30^{\circ} \mathrm{C}$ and $180 \mathrm{rpm}$. The cultures were harvested by centrifugation $\left(4,000 \times g, 15 \mathrm{~min}, 4^{\circ} \mathrm{C}\right)$, resuspended in HEPES buffer $(20 \mathrm{mM}$ HEPES, $200 \mathrm{mM} \mathrm{NaCl}, 20 \mathrm{mM} \mathrm{KCl}, 40 \mathrm{mM}$ imidazole, $\mathrm{pH}$ 8.0 ), and subsequently disrupted using a microfluidizer (M110-L, Microfluidics). The cell debris was removed by centrifugation $\left(50,000 \times g, 20 \mathrm{~min}, 4^{\circ} \mathrm{C}\right)$. The supernatant was loaded onto Ni-NTA FF-HisTrap columns (GE Healthcare) for affinity purification via the hexahistidine tag. The columns were washed with HEPES buffer $(10 \times$ column volume $)$ and eluted with HEPES buffer containing $250 \mathrm{mM}$ imidazole. Prior to size exclusion chromatography (SEC), the GB1-tag was cleaved off by adding $0.8 \mathrm{mg}$ purified TEV protease directly to the eluate and incubating under constant rotation at $20^{\circ} \mathrm{C}$ for $3 \mathrm{~h}$. Cleaved His-tagged GB1 and remaining TEV protease were removed via a second Ni-NTA purification after buffer exchange to HEPES buffer containing $40 \mathrm{mM}$ imidazole using an Amicon Ultra-10 K centrifugal filter (Merck Millipore). The tag-free protein was subjected to SEC using a Superdex S75 Increase $10 / 300$ column equilibrated in HEPES buffer without imidazole and a $\mathrm{pH}$ of 7.5 . The peak fractions were analyzed using a standard sodium dodecyl sulfate polyacrylamide gel electrophoresis (SDS-PAGE) protocol, pooled, and concentrated with Amicon Ultra-10 K centrifugal filters.

\section{Production and Purification of Membrane Proteins}

The plasmids pFA659 and pFA670 encoding full-length Vmp2 and Vmp1 were transformed in E. coli OverExpress ${ }^{\mathrm{TM}} \mathrm{C} 43$ (DE3; Sigma-Aldrich). Transformants were grown in TerrificBroth medium [24 g/l yeast extract, $20 \mathrm{~g} / \mathrm{l}$ tryptone, $4 \mathrm{ml} / \mathrm{l}$ glycerol, buffered with $10 \%$ phosphate buffer $\mathrm{pH} 7.4(0.17 \mathrm{M}$ $\mathrm{KH}_{2} \mathrm{PO}_{4}, 0.72 \mathrm{M} \mathrm{K}_{2} \mathrm{HPO}_{4}$ )] under constant shaking at $180 \mathrm{rpm}$ and $37^{\circ} \mathrm{C}$ to an $\mathrm{OD}_{600}$ of $0.5-0.6$. The cultures were then cooled to $20^{\circ} \mathrm{C}$, induced with $0.2 \mathrm{M}$ Isopropyl- $\beta$-Dthiogalactopyranosid (IPTG), and incubated for $20 \mathrm{~h}$ at $20^{\circ} \mathrm{C}$ and $180 \mathrm{rpm}$. The cultures were harvested by centrifugation $\left(4,000 \times g, 15 \mathrm{~min}, 4^{\circ} \mathrm{C}\right)$, resuspended in Tris-buffer $(50 \mathrm{mM}$ Tris-Base, $300 \mathrm{mM} \mathrm{NaCl}, 40 \mathrm{mM}$ imidazole, $\mathrm{pH}$ 8.0), and subsequently disrupted using a microfluidizer (M110-L, Microfluidics). The cell debris was removed by centrifugation $\left(8,000 \times g, 20 \mathrm{~min}, 4^{\circ} \mathrm{C}\right)$ and the supernatant was centrifuged $\left(115,000 \times g, 1 \mathrm{~h}, 4^{\circ} \mathrm{C}\right)$ using a fixed-angle rotor $(70 \mathrm{Ti}$, Beckmann) in an ultracentrifuge (Optima XPN-80, Beckmann). The pellet was resuspended in $10 \mathrm{ml}$ Tris-Buffer using a Douncehomogenizer (Carl Roth). The homogenized pellet was mixed with $10 \mathrm{ml}$ Tris-Buffer containing either $2 \% \quad(\mathrm{w} / \mathrm{v})$ Lauryldimethylamine-N-Oxide (LDAO) or 2\% (w/v) Dodecyl$\beta$-D-maltosid (DDM) for Vmp1 and Vmp2, respectively, and incubated for $2.5 \mathrm{~h}$ at $4^{\circ} \mathrm{C}$ under constant rotation. The solubilized membrane was again centrifuged $(115,000 \times g, 1 \mathrm{~h}$, $4^{\circ} \mathrm{C}$ ). The supernatant was loaded onto $1 \mathrm{ml} \mathrm{Ni-NTA} \mathrm{FF-HisTrap}$ columns (GE Healthcare) for affinity purification via the hexahistidine tag. The detergent concentration was lowered to $0.1 \%(\mathrm{w} / \mathrm{v})$ during the Ni-NTA purification of both proteins. Prior to SEC, the Mistics-tag was cleaved off by adding $0.8 \mathrm{mg}$ purified TEV directly to the eluate and incubating under constant rotation at $20^{\circ} \mathrm{C}$ for $3 \mathrm{~h}$. Cleaved His-tagged Mistics and remaining TEV protease were removed via a second Ni-NTA purification after buffer exchange to Tris buffer containing $40 \mathrm{mM}$ imidazole in an Amicon centrifugal filter (Merck Millipore) with adequate cutoff. The protein was subjected to SEC using a Superdex 200 Increase 10/300 column equilibrated in HEPES-buffer (20 mM HEPES, $200 \mathrm{mM} \mathrm{NaCl}, 20 \mathrm{mM}$ $\mathrm{KCl}, \mathrm{pH} 7.5)$ containing either $0.1 \%(\mathrm{w} / \mathrm{v}) \mathrm{LDAO}$ or $0.03 \%$ (w/v) DDM for Vmp1 and Vmp2, respectively. The peak fractions were analyzed using a standard SDS-PAGE protocol, pooled, and concentrated with appropriate Amicon centrifugal filters. 


\section{Multi-Angle Light Scattering}

Multi-angle light scattering coupled size-exclusion chromatography (SEC-MALS) was performed using an Äkta PURE system (GE Healthcare) with a Superdex 200 Increase 10/300 column attached to a MALS detector 3609 (Postnova Analytics) and a refractive index detector 3150 (Postnova Analytics). The column was equilibrated with $0.2 \mu \mathrm{m}$ filtered HEPES buffer (20 mM HEPES, $200 \mathrm{mM} \mathrm{NaCl}, 20 \mathrm{mM} \mathrm{KCl}$, $\mathrm{pH} 7.5)$ containing either $0.1 \%(\mathrm{w} / \mathrm{v})$ LDAO or $0.03 \%(\mathrm{w} / \mathrm{v})$ DDM for Vmp1 and Vmp2, respectively. For each measurement, $100 \mu \mathrm{l}$ of a $50 \mu \mathrm{M}$ protein solution was injected.

\section{Mass Photometry}

Mass photometry experiments were performed using a OneMP mass photometer (Refeyn Ltd., Oxford, United Kingdom). Data acquisition was performed using AcquireMP (Refeyn Ltd. v2.3). Mass photometry movies were recorded at $1 \mathrm{kHz}$, with exposure times varying between 0.6 and $0.9 \mathrm{~ms}$, adjusted to maximize camera counts while avoiding saturation. Microscope slides $(70 \times 26 \mathrm{~mm})$ were cleaned $5 \mathrm{~min}$ in $50 \%(\mathrm{v} / \mathrm{v})$ isopropanol (HPLC grade in Milli-Q $\mathrm{H}_{2} \mathrm{O}$ ) and pure Milli-Q $\mathrm{H}_{2} \mathrm{O}$, followed by drying with a pressurized air stream. Silicon gaskets to hold the sample drops were cleaned in the same manner fixed to clean glass slides immediately prior to measurement. The instrument was calibrated using NativeMark Protein Standard (Thermo Fisher) immediately prior to measurements. Immediately prior to mass photometry measurements, protein stocks were diluted directly in HEPES buffer. Typical working concentrations of Vmp1 and Vmp2 were 25-50 nM for the actual measurement. Each protein was measured in a new gasket well (i.e., each well was used once). To find focus, $18 \mu \mathrm{l}$ of fresh room temperature buffer was pipetted into a well, and the focal position was identified and locked using the autofocus function of the instrument. For each acquisition, $2 \mu \mathrm{l}$ of diluted protein was added to the well and thoroughly mixed. The data were analyzed using the DiscoverMP software.

\section{Confocal Light Microscopy}

The proliferation of $U$. maydis in infected maize leaf tissue was visualized by confocal microscopy as described previously (Tanaka et al., 2014). A leaf area of $1 \mathrm{~cm}^{2}$ located $2 \mathrm{~cm}$ below the injection site was excised 2 days post-infection (dpi). The leaf samples were destained with ethanol and treated with $10 \%(\mathrm{w} / \mathrm{v})$ potassium hydroxide at $85^{\circ} \mathrm{C}$ for $4 \mathrm{~h}$. The fungal hyphae were stained with Wheat Germ Agglutinin-Alexa Fluor 488 (WGA-AF488, Invitrogen). The plant cell walls were stained with propidium iodide (SigmaAldrich) by incubating decolorized samples in staining solution $\left(1 \mu \mathrm{g} / \mathrm{ml}\right.$ propidium iodide, $10 \mu \mathrm{g} \mathrm{ml}^{-1}$ WGA-AF488) and observed with a TCS-SP8 confocal laser-scanning microscope (Leica Microsystems) under the following conditions: WGA-AF488: excitation at $488 \mathrm{~nm}$ and detection at 500-540 nm; propidium iodide: excitation at $561 \mathrm{~nm}$ and detection at 580-660 nm.

\section{Fungal Stress Assays}

Fungal strains were grown in $\mathrm{YEPS}_{\text {light }}$ medium $[1 \%(\mathrm{w} / \mathrm{v})$ yeast extract, $0.4 \%(\mathrm{w} / \mathrm{v})$ peptone, and $0.4 \%(\mathrm{w} / \mathrm{v})$ sucrose] to an
$\mathrm{OD}_{600}$ of 1.0. The cells were pelleted and resuspended in sterile double distilled $\mathrm{H}_{2} \mathrm{O}$ to an $\mathrm{OD}_{600}$ 0.1. For the induction of filament formation, $10 \mu \mathrm{l}$ of serial dilutions were spotted on potato-dextrose charcoal plates (Holliday, 1974). The stress assays were performed on CM plates (Holliday, 1974) supplemented with $750 \mu \mathrm{M}$ calcufluor white (Sigma-Aldrich), $3 \mathrm{mM}$ hydrogen peroxide $\left(\mathrm{H}_{2} \mathrm{O}_{2}\right), 1 \mathrm{M} \mathrm{NaCl}$, or $1 \mathrm{M}$ sorbitol. Images were taken after over-night incubation at $28^{\circ} \mathrm{C}$.

\section{Statistical Analysis}

Disease symptoms of infected plants were scored at $12 \mathrm{dpi}$ using the previously established scoring scheme by Kämper et al. (2006). Disease symptoms were quantified based on three biological replicates and are presented as stacked histograms. Significant differences among disease symptoms within individual disease categories were determined by Student's $t$-test. The raw data of all infection assays and the statistical analysis can be found Supplementary Table S5.

\section{Accession Numbers}

The genes and encoding protein sequences from $U$. maydis are available at NCBI under the following accession numbers: vmp1 (UMAG_00032), XP_011386009.1; vmp2 (UMAG_01689), XP_011387666.1; UMAG_01713, XP_011387687.1; UMAG_04185, XP_011390672.1; UMAG_10491, XP_011390314.1; and UMAG_03474, XP_011389930.1.

\section{RESULTS}

\section{Identification of Membrane Proteins Critical for Pathogenic Development of U. maydis}

To identify membrane proteins that show an increase in transcript abundance during infection stages associated with biotrophic development of $U$. maydis, we analyzed the transcriptomic data obtained by Lanver et al. (2018). Highly upregulated proteinencoding genes were then examined for the presence of potential transmembrane helices (TMs) using the Consensus Constrained TOPology prediction web server CCTOP (Supplementary Figure S1; Dobson et al., 2015). By this approach, we could identify six genes strongly elevated during infection and their respective proteins containing at least one predicted TM. They show their strongest expression 2-4 dpi while not induced in axenic culture under non-infective conditions (Figure 1A). These proteins are UMAG_00032, UMAG_01689, UMAG_01713, UMAG_03474, UMAG_04185, and UMAG_10491.

To evaluate these proteins' impact on virulence, we deleted their respective genes in the solopathogenic $U$. maydis strain SG200 (Kämper et al., 2006). The gene deletion was performed using a CRISPR-Cas9-based approach as described by Schuster et al. (2016). A donor DNA was supplied to delete the respective ORFs from the genome while keeping the surrounding genetic environment intact (Supplementary Figure S2). The deletion of four genes resulted in a wild-type-like behavior during maize 


\section{A}
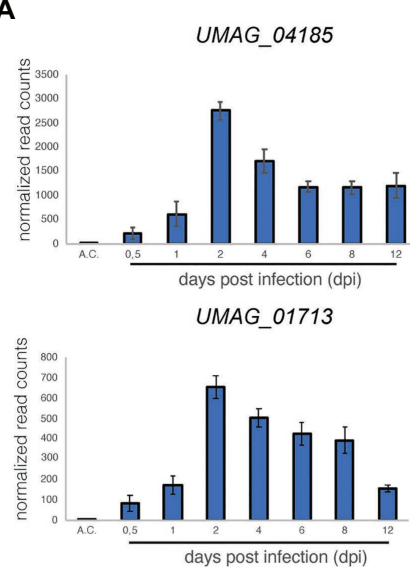

UMAG_01689

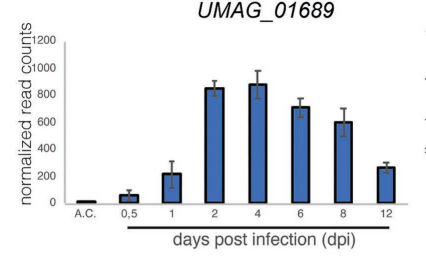

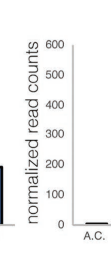
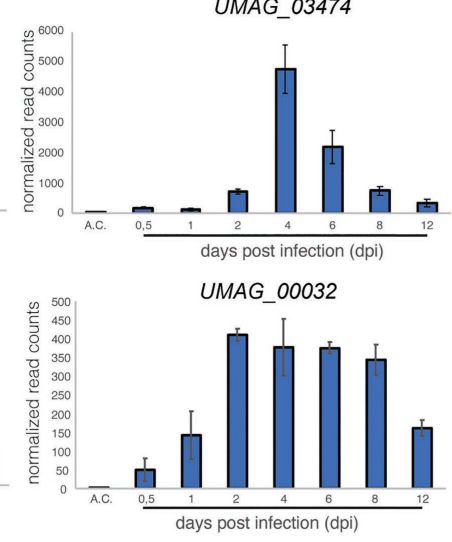

UMAG_03474

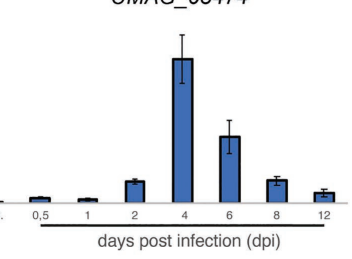

UMAG_10491
B

.

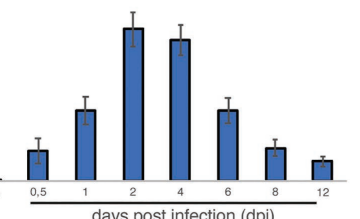

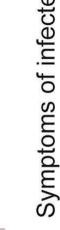

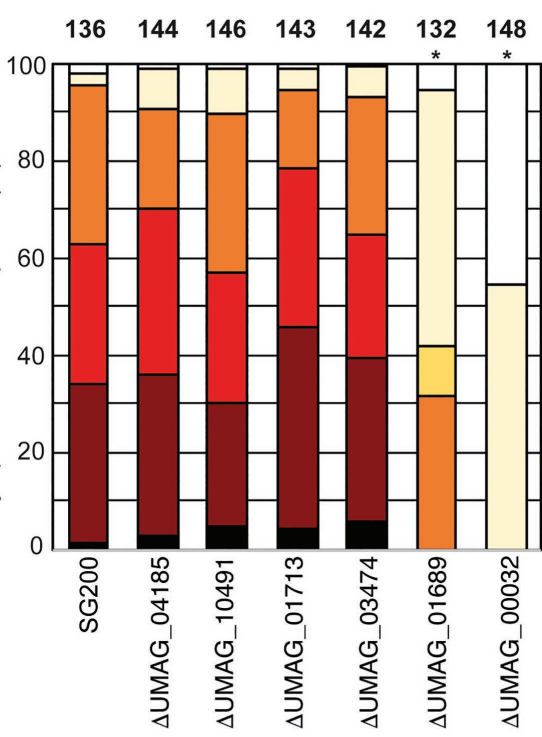

$\square$ No infection sym
$\square$ Ligula swelling
$\square$ Normal tumors

Dead plants

FIGURE 1 | Identification of a transmembrane protein important for virulence (A) The expression pattern of genes encoding transmembrane proteins in Ustilago maydis during plant infection re-analyzed from RNA sequencing data (Lanver et al., 2018). A.C., expression level in axenic culture. The numbers below the bars indicate the days post inoculation (dpi). Error bars indicate \pm standard deviation. (B) Virulence assay of genes encoding transmembrane proteins in the $U$. maydis SG200 background. Disease symptoms were quantified on maize leaves 12 days post infection (dpi). Similar results were observed in three independent experiments. Shown is the mean percentage of plants placed in a particular disease category. The number of infected plants is indicated above the bars. The asterisk indicates a significant difference in infection symptoms between SG200, SG200_UMAG_00032, and SG200_UMAG_01689.

infection experiments (UMAG_01713, UMAG_03474, UMAG_04185, and UMAG_10491), the two other genes (UMAG_00032 and UMAG_01689) lead to attenuation in virulence (Figure 1B). To investigate whether the differences in phenotypical symptoms between the deletion strains of UMAG_00032, UMAG_01689, and SG200 are significant, we scored the disease symptoms of each infected plant using a previously established scoring scheme (Kämper et al., 2006). For the significance analysis, we performed a two-sided Student's $t$-test. Our analysis for each category confirmed that the differences are significant, with values of $p$ below 0.05 for several categories (Supplementary Table S5).

Our results reveal two TM proteins that strongly impact the virulence of $U$. maydis during maize infection. Therefore, we named both genes vmp1 (UMAG_00032) and vmp2 (UMAG_01689) for Vmp1 and Vmp2.

\section{Vmp1 and vmp2 Are Conserved Among Related Smut Species}

Vmp1 encodes a protein of 142 amino acids (aa), whereas $v m p 2$ encodes a 335 aa long protein. Both proteins contain an N-terminal signal peptide (SP) of 25 aa, as predicted by SignalP-5.0 (Armenteros et al., 2019). Our in silico analyses indicate that both proteins harbor one TM helix spanning the residues 60-77 in Vmp1 and residues 100-115 in Vmp2
(Supplementary Figure S1). The N-terminal domain (NTD) of both proteins is predicted to be extracellular (Supplementary Figure S1).

In a next step, we analyzed the genetic context of both proteins in $U$. maydis and compared it to related smut fungi. Using the Basic Local Alignment Search Tool (BLAST), we identified Vmp1 orthologs in the genomes of Pseudozyma hubeiensis SY62, Kalmanozyma brasiliensis GHG001, Sporisorium reilianum SRZ2, Ustilago trichophora, Sporisorium scitamineum, Moesziomyces antarcticus, Moesziomyces aphidis DSM 70725, and Testicularia cyperi with identities ranging from 58 to $34 \%$ (determined by CLUSTAL2.1; Supplementary Figure S3A). However, it was absent in Ustilago hordei or Ustilago bromivora with the genetic context being similar to U. maydis (Figure 2A). A protein related to Vmp1 was also identified in the genome of T. cyperi a pathogen of Rhynchospora spp. (Kijpornyongpan et al., 2018). The genetic context showed differences to the closely related species due to the ancestral nature of T. cyperi (Figure 2A).

The neighboring genes encode a proline dehydrogenase (UMAG_00030), a TM protein of unknown function (UMAG_00031), a $\mathrm{Zn}_{2}$-C6 fungal-type transcription factor (UMAG_10009), and a putative Major Facilitator Superfamily (MFS) transporter (UMAG_00034; Figure 2A). These genes are also induced during axenic growth and might thus not be directly related to virulence. However, UMAG_00034 shows 
A

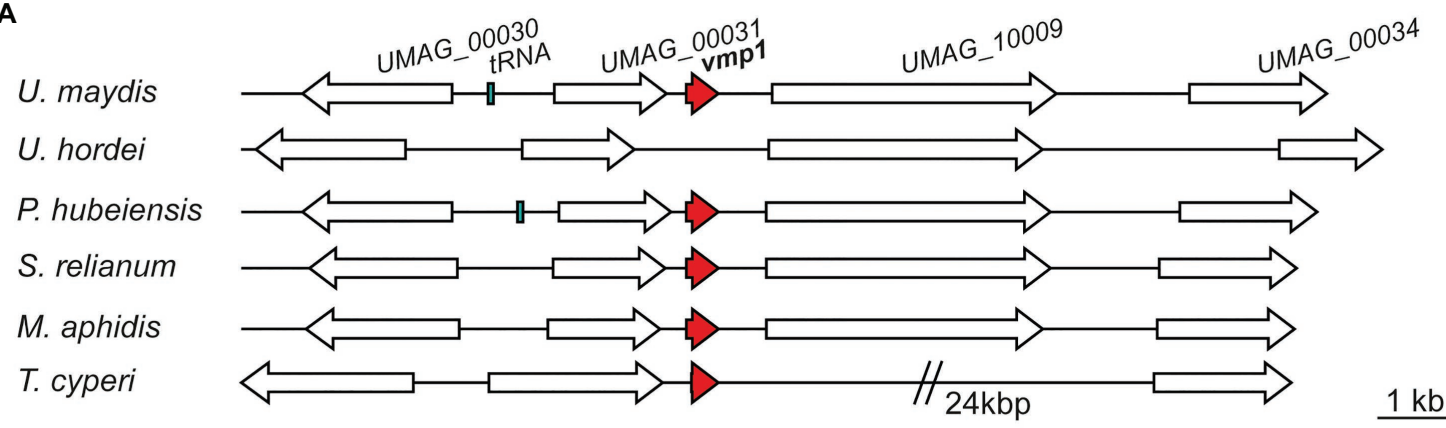

B

U. maydis

U. hordei

P. hubeiensis

S. relianum

M. aphidis

T. cyperi

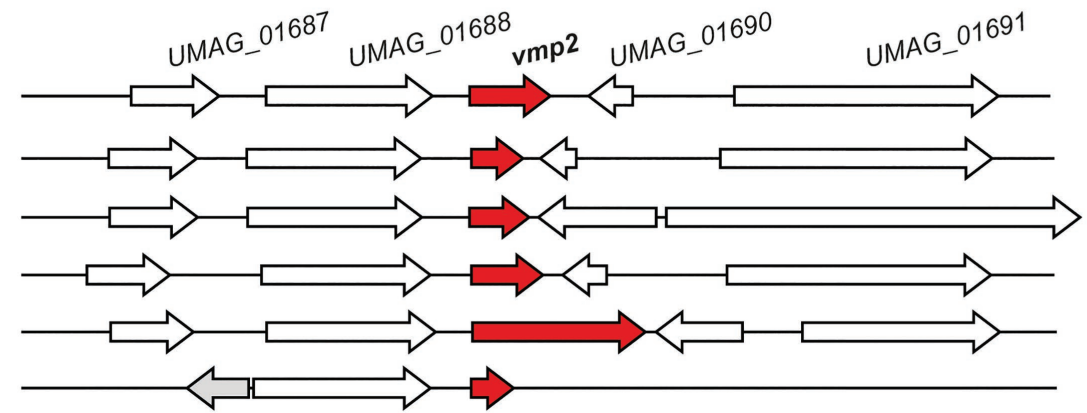

$1 \mathrm{~kb}$

FIGURE 2 | Vmp1 and Vmp2 orthologs are conserved in related smut fungi. Schematic picture of gene loci encoding Vmp1 (A) and Vmp2 (B) and orthologs in the related smut pathogens Ustilago hordei, Pseudozyma hubeiensis, Sporisorium relianum, Moesziomyces aphidis, and Testicularia cyperi. White arrows indicate genes found in all of the respective species, while the gray gene was solely present in the genome of T. cyperi.

elevated transcript levels between 24 and $48 \mathrm{~h}$ post-infection while not induced during axenic growth (Lanver et al., 2018).

We also identified orthologs of Vmp2 in a variety of related smut fungi (Supplementary Figure S3B). Namely, P. hubeiensis SY62, U. bromivora, Sporisorium graminicola, S. reilianum SRZ2, $U$. hordei, K. brasiliensis GHG001, U. trichophora, M. antarcticus, S. scitamineum, and T. cyperi. Here, the sequence identities ranged from 43 to 36\% (Supplementary Figure S3B). Notably, Vmp2 is highly conserved from amino acid 82-195 (within the Vmp2 sequence from U. maydis), while the C-terminus shows a higher degree of deviation in the investigated orthologs (Supplementary Figure S3B). In Ustilaginaceae, the loci of $v m p 2$ are similarly to $v m p 1$ highly syntenic although the intergenic region toward UMAG_01690 and its orthologs shows some length differences (Figure 2B). The neighboring genes include an OBG-type G-domain-containing protein (UMAG_01687), a putative nuclear transport factor (UMAG_01688), a secreted effector protein of unknown function (UMAG_01690), and a DNA helicase (UMAG_01691; Figure 2B).

\section{Vmp1 Allows Fungal Infection After Penetration of the Plant Epidermis}

The vmp1 deletion strain showed the strongest reduction in virulence with tumor formation being entirely abolished in infected plants (Figures 3A,B). Anthocyanin production was observed in the vicinity of the infection site, a universal sign of infections, and thus the presence of infectious hyphae

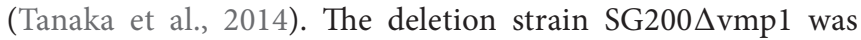

complemented by integrating a single copy of vmp1 into the ip locus (SG200 $\Delta$ vmp1-vmp1, Figure 3A). The complementation

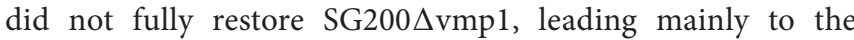
formation of smaller tumors and larger ones only to a lesser extent (Figures 3A,B). To investigate locus specific effects (e.g., genome structure effects) resulting from a deletion of the entire open reading frame (ORF) of $v m p 1$, we introduced a point mutation into $v m p 1$ resulting in a frameshift. The SG200vmp1-mut strain still showed a strong attenuation in

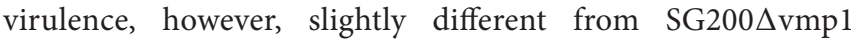
(Figure 3A). Thus, locus specific effects might be one explanation why our complementation in the ip locus did not fully rescue the mutant phenotype.

Furthermore, we wanted to know whether SG200 $\Delta$ vmp1 remains able to grow inside vascular bundles and elicits a plant defense response or whether fungal growth is arrested after penetration of the epidermal layer. To detect differences in host colonization, we visualized fungal hyphae by staining with WGA-AF488 at 2 and 6 dpi (Figure 3C). It became

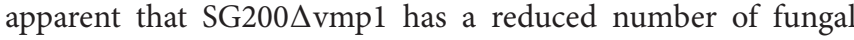
hyphae on the plant leaf surface combined with less proliferation (Figure 3C). However, hyphae could still penetrate the epidermal layer and grow inside the vascular bundles (Figure 3C). Fungal growth was seemingly arrested at this stage as the amount of fungal material inside the plant leaves was not drastically increased at $6 \mathrm{dpi}$ (Figure 3C). To rule out that the reduced virulence was due to reduced growth and stress sensitivity, we grew SG200 $\Delta$ vmp1 in the presence of $\mathrm{NaCl}$, sorbitol, 
A

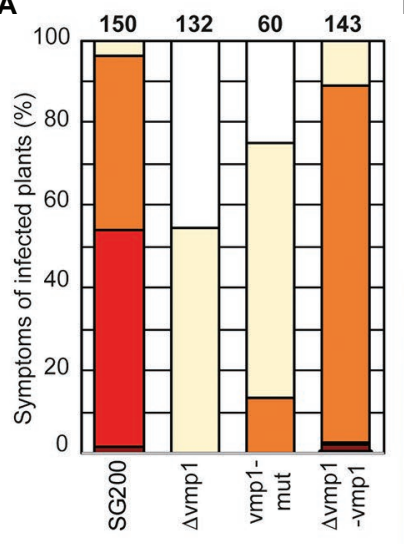

$\square$ No infection symptoms $\square$ Chlorosis

L Ligula swelling

$\square$ Small tumors

Normal tumors

$\square$ Heavy tumors

Dead plants
B

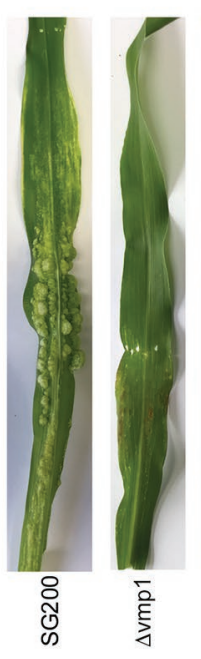

C
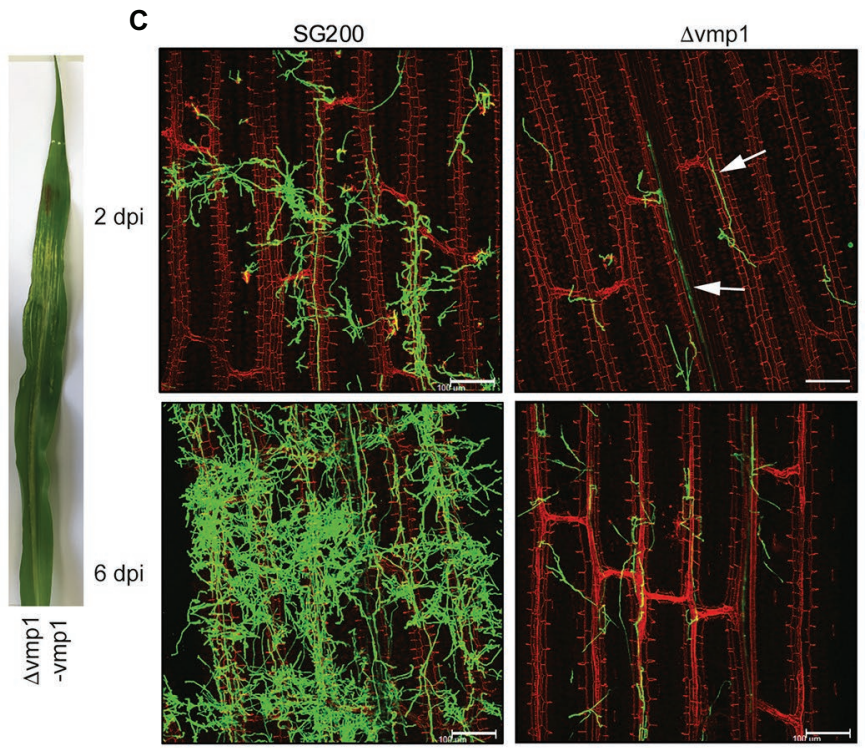

FIGURE 3 | Vmp1 is required for virulence (A) Virulence assay of the SG200 $\Delta$ vmp1 mutant strain deleted for the entire coding sequence of vmp1, the SG200vmp1-mut strain that harbors a point mutation within the coding sequence of vmp1 and SG200 $\Delta$ vmp1-vmp1 complementation strain in an U. maydis SG200 background. The mean percentage of disease symptoms in the different categories is shown, which is quantified based on three biological replicates. The number of infected plants is indicated above the bars. (B) Macroscopic pictures of maize leaves 12 dpi with U. maydis SG200, SG200 $\Delta$ vmp1, and SG200 $\Delta$ vmp1vmp1. (C) Leaf tissues infected with SG200 and SG200 $\Delta$ vmp1 were stained with WGA-AF488 and propidium iodide at 2 and 6 dpi. Green color indicates fungal hyphae and red color indicates leaf vascular bundles. Bar $=100 \mu \mathrm{m}$.

calcofluor white, and $\mathrm{H}_{2} \mathrm{O}_{2}$. However, mutant strains were indistinguishable from SG200 (Supplementary Figure S4).

In conclusion, we show that the TM protein encoded by $v m p 1$ is essential for full virulence and might be important for establishing the biotrophic interface. It is conserved among related smut fungi (Supplementary Figure S3A) indicating that its function might also be conserved among these relatives.

\section{Vmp2 Is Important for Fungal Infection}

The deletion of $v m p 2$ led to a strong reduction in virulence of $U$. maydis, with solely small tumors being formed (Figure 4A). We complemented SG200 $\Delta$ vmp2 by integrating a single copy of $v m p 2$ into the ip locus (SG200 $\Delta$ vmp2-vmp2, Figures $4 \mathbf{A}, \mathbf{B}$ ). This complementation could fully restore the phenotype of SG200 $\Delta$ vmp2. To rule out that the deletion of $v m p 2$ leads to altered growth of $U$. maydis under stress conditions, we grew SG200 $\Delta$ vmp2 in the presence of $\mathrm{NaCl}$, sorbitol, calcofluor white, and $\mathrm{H}_{2} \mathrm{O}_{2}$ and did not detect differences from SG200 (Supplementary Figure S4).

In the next step, we aimed to understand how deleting the two predicted soluble domains would impact the function of Vmp2 in vivo (Supplementary Figure S1). We generated two constructs deleting either the predicted extracellular NTD or the cytosolic C-terminal domain (CTD) and transformed U. maydis SG200 to perform infection assays (Supplementary Figure S2D). Our experiments show that SG200vmp $2_{\Delta \text { CTD }}$ phenocopies SG200 $\Delta v \mathrm{vmp} 2$, while SG200vmp $2_{\Delta \mathrm{NTD}}$ is less attenuated in virulence (Figures $4 \mathbf{A}, \mathbf{B}$ ).

Taken together, we can show that $v m p 2$ is an essential player for the infection process in $U$. maydis and potentially related organisms. Additionally, our infection experiments indicate that the CTD of Vmp2 is important for full virulence.

\section{Vmp1 Is a Membrane Protein}

To allow for a biochemical investigation of Vmp1, we cloned the ORF without the signal peptide (residues 1-20) for heterologous protein production in E. coli (see section "Materials and Methods"). First expression and solubility tests did not allow to purify the full-length protein in amounts sufficient for biochemical analysis. Thus, we generated a construct that includes an N-terminal Mistics-tag (MstX) separated by a TEV protease cleavage site. This 110 amino acid long protein tag contains four transmembrane helices and inserts autonomously in the membrane. It has been used to improve the expression of membrane proteins in several cases (Roosild et al., 2005). In our case, the production of MstX-Vmp1 was drastically enhanced compared to protein production without the fusion-tag. Attempts to solubilize MstX-Vmp1 from the membrane fraction using Dodecyl- $\beta$-D-maltosid (DDM) failed, and thus, we tested a variety of commercially available detergents. Solubilization was only achieved employing Lauryldimethylamine-N-Oxide (LDAO). Notably, all attempts to cleave the MstX tag via TEV cleavage only resulted in inefficient and partial cleavage. It is likely that the spacing between the membrane-embedded MstX and the membrane spanning helix within Vmp1 (residues 60-77) might not allow for a proper TEV recognition and cleavage. Consequently, we used the full-length fusion protein for biochemical analysis. 

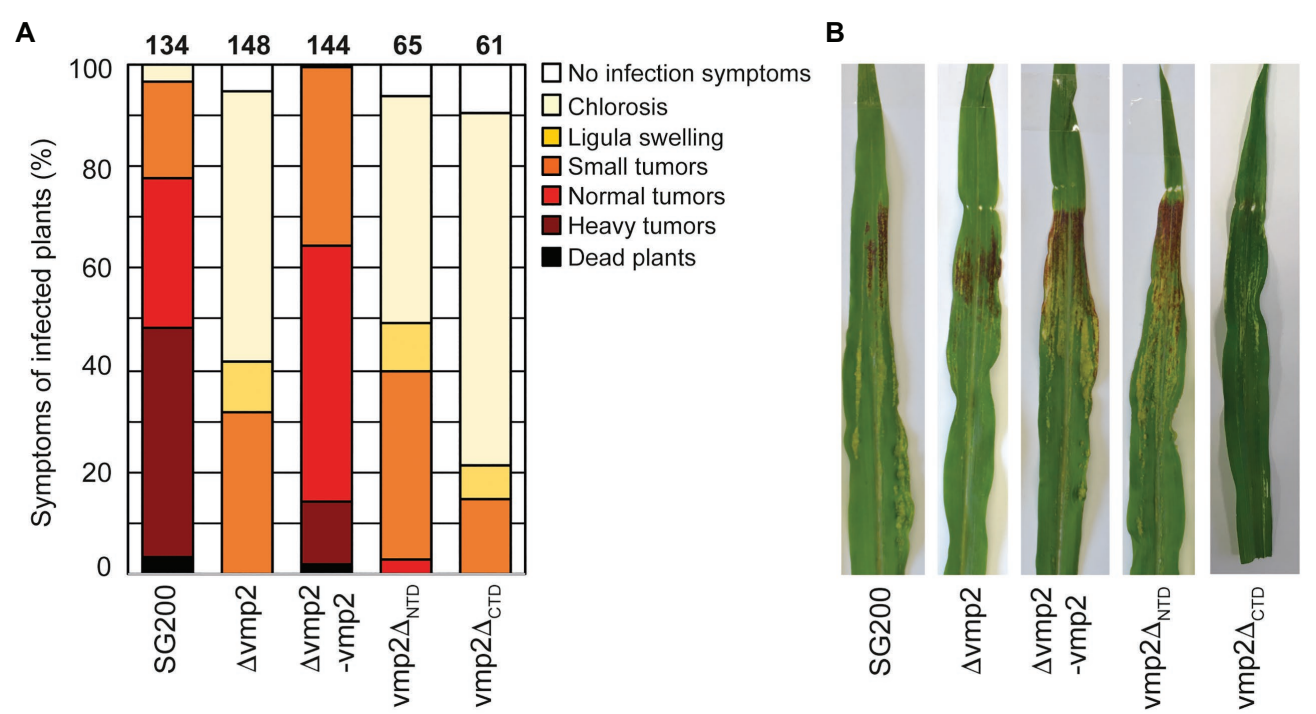

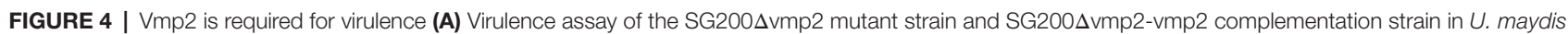
SG200 background. Disease symptoms were quantified based on three biological replicates. The number of infected plants is indicated above the bars.

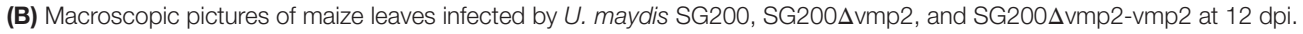

Purified MstX-Vmp1 was subjected to SEC-MALS using a Superose 6 Increase 3.2/300 column equilibrated with SEC buffer including $0.1 \%$ LDAO (see section "Materials and Methods"). The protein eluted in a single peak at $1.62 \mathrm{ml}$ corresponding to $90 \mathrm{kDa}$ according to the calibration calculation for this column (Figure 5A). Our analysis with MALS and refractive index resulted in a mass of $113 \pm 17 \mathrm{kDa}$ and thus yielded a slightly higher molecular weight (Figure 5A). The calculated mass of the MstX-Vmpl fusion protein is around $31 \mathrm{kDa}$. MALS allowed us to clearly distinguish between empty micelles and the membrane protein-detergent complexes. Notably, the molecular weight of free LDAO micelles was found to be $40 \pm 5 \mathrm{kDa}$ in our experiments and thus a bit larger than $16-20 \mathrm{kDa}$ reported in literature (Timmins et al., 1988). As membrane proteins are likely not embedded into detergent micelles but rather form membrane protein-detergent complexes (Chaptal et al., 2017), our results indicate that two or three Vmp1 molecules would be encaged by LDAO detergent molecules.

To achieve a better resolution of Vmp1 oligomerization, we employed mass photometry, a method that became recently available and allows rapid and reliable determination of the dynamic molecular weight of macromolecules in solution (Soltermann et al., 2020; Olerinyova et al., 2021). We firstly used a final concentration of $25 \mathrm{nM}$ MstX-Vmp1 for mass photometric analysis which was achieved by rapid 1:10 dilution of a $250 \mathrm{nM}$ solution into SEC buffer without detergent. Approximately $60 \%$ of MstX-Vmp1 had a measured mass of $42 \mathrm{kDa}$ (Figure 5B), suggesting a monomer of MstX-Vmp1 and $~ 50$ LDAO detergent molecules (11 kDA). A subfraction higher molecular weight assemblies was also visible; however, gaussian fitting was not possible at this concentration. When using $50 \mathrm{nM}$ of MstX-Vmp1, the main fraction of $60 \%$ contained molecules with a mass of $42 \mathrm{kDa}$ and a slightly larger fraction of higher molecular weight assemblies were observed ranging from 100 to $200 \mathrm{kDa}$ compared to the $25 \mathrm{nM}$ sample (Figure 5C). To rule out that no empty LDAO micelles were detected, we subjected a buffer containing no protein and only LDAO at the working concentration of $0.01 \%$ to mass photometry. However, no events were detectable suggesting that micelles are not formed at this detergent concentration.

Taken together, we conclude that Vmpl mainly occurs as a monomer but might form higher oligomeric species at higher concentrations.

\section{Vmp2 Is a Dimeric Membrane Protein}

In a next step, we aimed to investigate $\mathrm{Vmp} 2$ after heterologous protein production in E. coli. Similar to Vmp1, the expression of full-length Vmp2 was insufficient for biochemical analyses and only the fusion of an N-terminal Mistics-tag allowed to obtain adequate amounts of membrane-bound protein. Vmp2 could be solubilized with DDM and was purified using a Superose 6 Increase 10/300 column (GE Healthcare) equilibrated with SEC buffer and $0.03 \%$ DDM (see section "Materials and Methods"). The protein eluted at $17.22 \mathrm{ml}$ corresponding to a molecular weight of approximately $83 \mathrm{kDa}$ (Figure 6A).

We again employed mass photometry to accurately determine the molecular weight of Vmp2 and investigate whether different oligomeric species might be visible even at nanomolar concentrations. However, using DDM as detergent, 0.03\% (w/v), which is equivalent to $600 \mu \mathrm{M}$, and thus generated a strong detergent background that did not allow us to distinguish between empty micelles and Vmp2. Thus, we investigated whether Vmp2 would be stable in LDAO or lauryl maltose neopentyl glycol (LMNG), a detergent that contains two DDM moieties and has a very low $\mathrm{CMC}$ at $10 \mu \mathrm{M}$ which is perfectly 
A $\begin{array}{ll}\text { molecular weight } & 669440 \\ \text { (MW) in kDa } & \nabla \nabla 87544\end{array}$
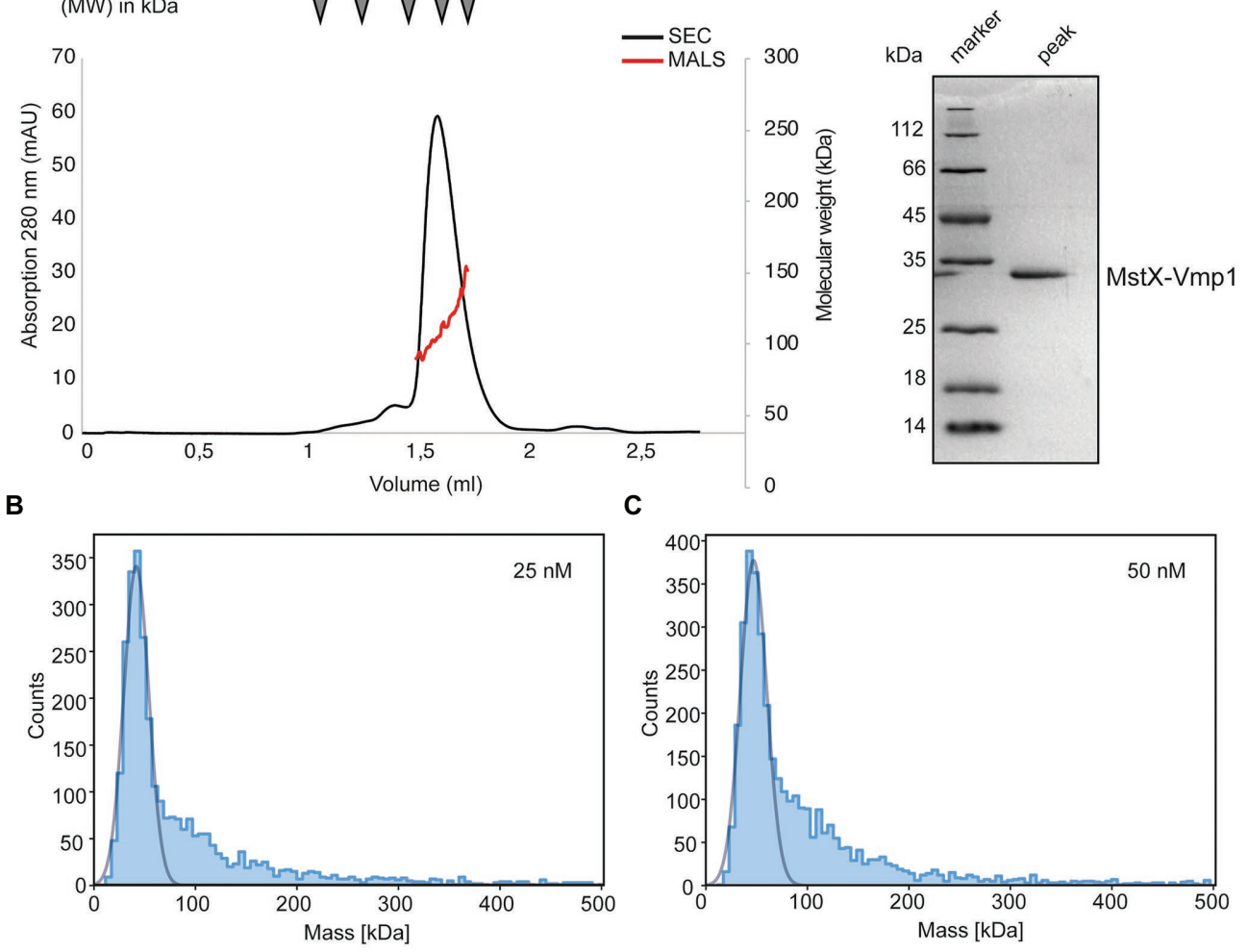

C

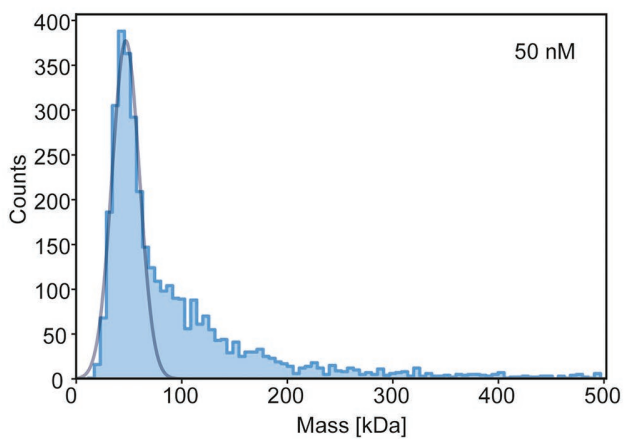

FIGURE 5 | Biochemical analysis of Vmp1. (A) Multi-angle-light scattering coupled size-exclusion chromatography (SEC-MALS) of full length MstX-Vmp1. The black line depicts the absorption at $280 \mathrm{~nm}$, while the red line corresponds to the molecular weight as determined by MALS. The inset shows a SDS-PAGE of the peak fraction. (B,C) Mass photometry of Vmp1 in $0.1 \%$ LDAO at 25 and $50 \mathrm{nM}$ concentration, respectively.

suited for mass photometry. We thus solubilized Vmp2 using DDM and exchanged the detergent during Ni-ion affinity chromatography and applied the protein to a Superose 6 Increase $10 / 300$ column equilibrated in $0.1 \%$ LDAO or $0.001 \%$ LMNG, respectively.

Firstly, Vmp2 purified in the presence of $0.1 \%$ LDAO was measured (Figure 6B). To remove excess detergent micelles during mass photometry, a stock solution at $1 \mu \mathrm{M}$ of Vmp2 was rapidly diluted 1:10 in SEC buffer without detergent. A Gaussian fit of the peak fraction contained $92 \%$ of all measured molecules at a MW of $81 \mathrm{kDa}$. In a second approach, we used Vmp2 solubilized in $0.001 \%$ LMNG and again rapidly diluted it 1:10 in SEC buffer containing no detergent. Here, we could fit $84 \%$ of all counts resulting in a MW of approximately $94 \mathrm{kDa}$ (Figure 6C). The mass differences between the LDAO and LMNG solubilized Vmp2 likely is a result from the different protein-detergent complex sizes formed by the two detergent molecules. As Vmp2 has a theoretical molecular weight of $32 \mathrm{kDa}$, the $81 \mathrm{kDa}$ would correspond to a dimer of Vmp2 and $\sim 75 \mathrm{LDAO}(17 \mathrm{kDa})$ detergent molecules, while the $94 \mathrm{kDa}$ suggest a Vmp2 dimer and $\sim 30$ LMNG $\left(\begin{array}{lll}30 & \mathrm{kDa}\end{array}\right)$ detergent molecules.

In summary, our mass photometry results are in agreement with the MW calculated from size exclusion chromatography and indicate the presence of a Vmp2 dimer.

\section{The CTD of Vmp2 Is Largely Unstructured and Does Not Contribute to Dimerization}

Next, we investigated the predicted cytosolic CTD of Vmp2. We subjected purified $\mathrm{Vmp} 2_{\mathrm{CTD}}$ to a Superdex 75 Increase $10 / 300$ column. The protein eluted at $9.28 \mathrm{ml}$ which corresponds to a molecular weight of $45 \mathrm{kDa}$ (Figure 6D). However, SEC-MALS unambiguously revealed a MW of $25 \pm 1.5 \mathrm{kDa}$ of Vmp $2_{\text {CTD }}$ (Figure 6D). Our secondary structure and disorder prediction through PSIPRED indicated that residues 200-335 are potentially disordered (Supplementary Figure S5). As disordered or non-globular proteins show a different migration behavior than the SEC-standard, this would explain the discrepancy between SEC and MALS MW calculation. In conclusion, we can show that Vmp2 is dimeric membrane protein with a CTD that is largely unstructured and does not contribute to dimerization.

\section{DISCUSSION}

In this study, we have identified six genes that are strongly induced between 0.5 and $2 \mathrm{dpi}$ and remain upregulated until 12 dpi (Figure 1A), while not being expressed in axenic culture. This expression pattern correlates with establishing and 
A
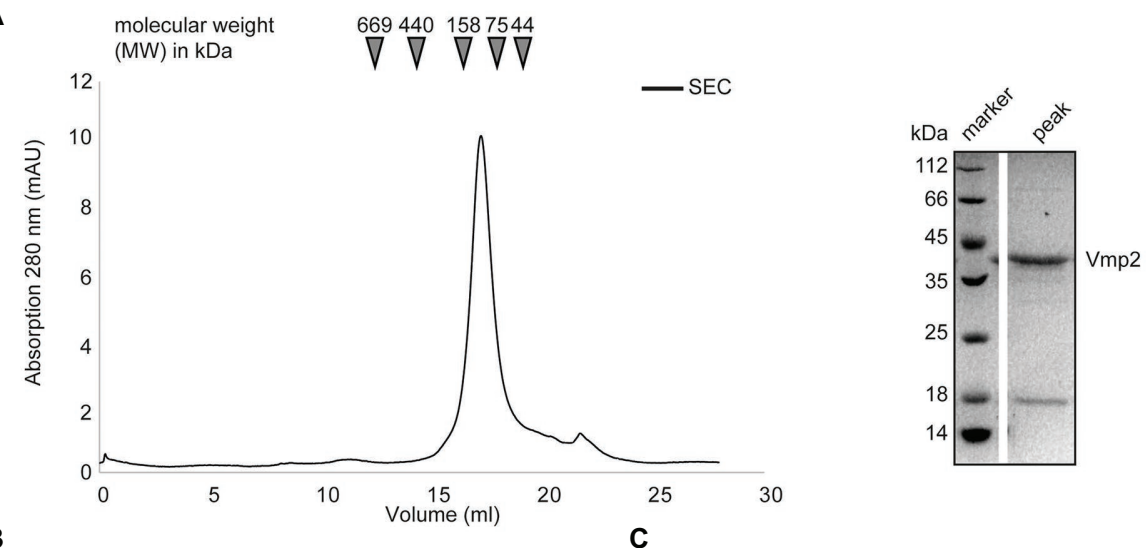

C
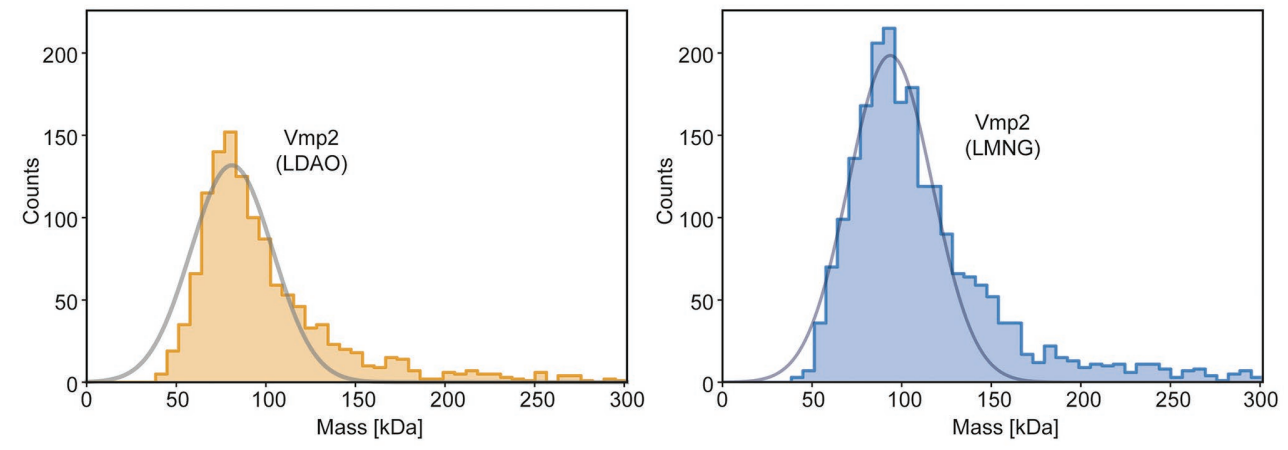

D

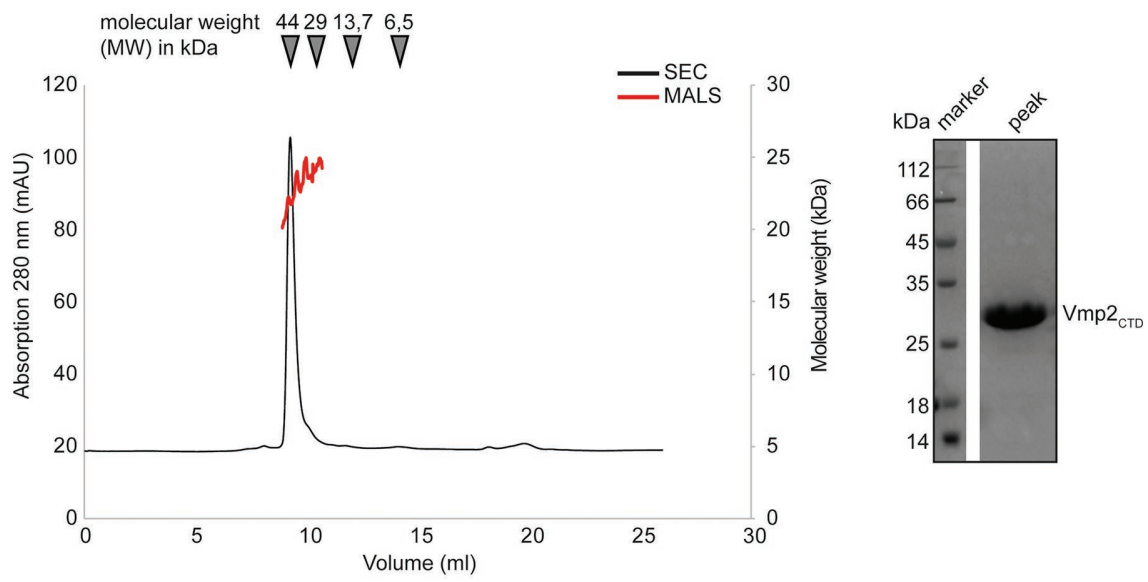

FIGURE 6 | Biochemical analysis of Vmp2. (A) SEC chromatogram of full length Vmp2. The inset shows a SDS-PAGE of the peak fraction. (B) Mass photometry of Vmp2 in 0.1\% LDAO. (C) Mass photometry of Vmp2 in 0.001\% LMNG. (D) SEC-MALS shows that the C-terminal domain (CTD) of Vmp2 (aa 120-335) is monomeric with an apparent molecular weight (MW) of $24 \mathrm{kDa}$. The black line depicts the absorption at $280 \mathrm{~nm}$, while the red line corresponds to the molecular weight as determined by MALS. The inset shows a SDS-PAGE of the peak fraction.

maintaining biotrophy, a critical feature of pathogenic development in smut fungi (Lanver et al., 2018). Our in silico analysis suggested that all of them harbor at least one transmembrane spanning helix, rendering them interesting targets as proteins associated with virulence in smut fungi are predominantly soluble effectors (Lanver et al., 2017). The deletion of two of them, subsequently named Vmp1 and Vmp2, resulted in a strong attenuation of virulence during maize infection, while growth of the deletion strains was neither affected in axenic liquid culture nor in the presence of various stress causing agents (Supplementary Figure S4). We can thus conclude that both Vmp1 and Vmp2 are important during pathogenic but not axenic growth of $U$. maydis. Attempts to reveal a potential function of these TM proteins by the prediction of functional domains yielded no results for Vmp1 and Vmp2 using the DomPred server embedded in the PSIPRED algorithm (Buchan and Jones, 2019).

To shed light on the function of Vmp1, we inspected the deletion strains in more detail. Deletion of Vmp1 led to a strong attenuation of fungal growth that was arrested after 
epidermal penetration (Figure 2C), although some hyphae were still visible growing inside vascular bundles. Notably, tumor formation on maize leaves inoculated with vmp1 mutant strains was not observed in infection experiments. Vmp1, thus, plays a critical role during the early infection stages. Notably, vmp1 mutant strains still elicited a plant defense response as anthocyanin production could still be observed on infected plant leaves.

Our biochemical analysis suggested that Vmp1 predominantly occurs as a monomer (Figure $\mathbf{5 B}$ ) as the cellular concentrations of Vmp1 will most likely be low. This is further supported by the gene expression data as $v m p 1$ shows the lowest expression of all six transmembrane protein encoding genes investigated (Figure 1A). During investigation of the genomic context of $v m p 1$, it became apparent that the gene UMAG_00031 is found in the same orientation upstream of vmp 1 in several related species. A recent study demonstrated that UMAG_00031 encodes a putative transmembrane protein potentially involved in $\mathrm{pH}$ regulation (Cervantes-Montelongo et al., 2020). In contrast to SG200 $v$ vmp1, UMAG_00031 mutant strains showed reduced growth under $\mathrm{pH}$ stresses as well as in the presence of sorbitol and $\mathrm{NaCl}$ (Cervantes-Montelongo et al., 2020). The study suggested UMAG_00031 to be a member of the Pal/ Rim pathway in $U$. maydis, a widely conserved signaling pathway involved in $\mathrm{pH}$ adaptation (Selvig and Alspaugh, 2011; Fonseca-García et al., 2012). However, our data indicate that $\mathrm{Vmp} 1$ is most likely not directly involved in $\mathrm{pH}$ adaptation or regulation. It might still play an accessory role in these processes serving, e.g., as adaptor protein. Here, future research might identify a connection toward $\mathrm{pH}$ related regulation to during plant infection.

Vmp2 (UMAG_01689) has already been identified to contribute to virulence in $U$. maydis (Uhse et al., 2018). In their study, the authors also showed that the fungal biomass is strongly reduced in infected plant leaves. However, as the knockout was only delivered as a proof-of-concept of their method to identify genes essential for virulence, no further information on Vmp2 was provided. Our data confirm the phenotype observed by Uhse and coworkers (Figure 4A). Furthermore, we can show that Vmp2 has a short N-terminal (NTD) and a long C-terminal domain (CTD). While deletion of the CTD phenocopies SG200Dvmp2, strains deleted for the NTD cause slightly more severe symptoms on infected plants. This suggests that the CTD is indispensable for virulence, but further experiments are required to dissect how the infection process is impacted by the truncation of Vmp2. Sequence alignments to homologs from other smut fungi show that the C-termini is highly variable, while the region surrounding the membrane spanning helix is conserved (Supplementary Figure S3). Our analysis by SEC-coupled MALS confirmed that the CTD is largely unstructured. Proteins containing unstructured regions have been characterized in the context of many scenarios and can make up substantial amounts of the total protein content (Van Der Lee et al., 2014). A possible scenario is that the unstructured region of Vmp1 becomes ordered in the context of an interaction partner.
Here, the sequence variability in related organisms suggests that this interface is species-specific. Another possible explanation might be that the unstructured domain is involved in membrane shaping or impacts the local membrane heterogeneity (Fakhree et al., 2019). A thorough investigation of the interactome of Vmp2 in planta might deliver an explanation for the role of CTD of Vmp2 during maize infection of $U$. maydis.

In conclusion, we here present two membrane proteins that act as virulence factors during maize colonization of $U$. maydis. While we deliver an initial characterization of the two proteins expanding the current knowledge on virulence associated membrane proteins of smut fungi, future research needs to address their precise functions.

\section{DATA AVAILABILITY STATEMENT}

The original contributions presented in the study are included in the article/Supplementary Material, further inquiries can be directed to the corresponding author.

\section{AUTHOR CONTRIBUTIONS}

FA designed the concept of the study. FA and PW performed the experiments, analyzed the data, and wrote the paper. All authors contributed to the article and approved the submitted version.

\section{FUNDING}

FA thanks the Peter und Traudl Engelhorn foundation for financial support.

\section{ACKNOWLEDGMENTS}

We thank Regine Kahmann for her continuous support throughout the work on this manuscript and her group for helpful discussions. We also thank Mariana Schuster for expert help with the CRISPR-Cas9 system, Xiaowei Han for assistance with strain construction and plant infection experiments, and Stefanie Reissmann for her help in the beginning of the project. We are grateful to Gert Bange for financial support and helpful discussion on the manuscript. We thank Georg Hochberg for access to the Refeyn One mass photometer and Pietro Giammarinaro for subsequent assistance with data collection.

\section{SUPPLEMENTARY MATERIAL}

The Supplementary Material for this article can be found online at: https://www.frontiersin.org/articles/10.3389/fpls.2021.669835/ full\#supplementary-material 


\section{REFERENCES}

Aichinger, C., Hansson, K., Eichhorn, H., Lessing, F., Mannhaupt, G., Mewes, W., et al. (2003). Identification of plant-regulated genes in Ustilago maydis by enhancer-trapping mutagenesis. Mol. Genet. Genomics. 270, 303-314. doi: 10.1007/s00438-003-0926-z

Armenteros, A., Juan, J., Tsirigos, K. D., Sønderby, C. K., Petersen, T. N., Winther, O., et al. (2019). SignalP 5.0 improves signal peptide predictions using deep neural networks. Nat. Biotechnol. 37, 420-423. doi: 10.1038/ s41587-019-0036-Z

Buchan, D. W. A., and Jones, D. T. (2019). The PSIPRED protein analysis workbench: 20 years On. Nucleic Acids Res. 47, W402-W407. doi: 10.1093/nar/gkz297

Cervantes-Montelongo, J. A., Silva-Martínez, G. A., Pliego-Arreaga, R., Guevara-Olvera, L., and Ruiz-Herrera, J. (2020). The UMAG_00031 gene from Ustilago maydis encodes a putative membrane protein involved in $\mathrm{PH}$ control and morphogenesis. Arch. Microbiol. 202, 2221-2232. doi: 10.1007/ s00203-020-01936-6

Chaptal, V., Delolme, F., Kilburg, A., Magnard, S., Montigny, C., Picard, M., et al. (2017). Quantification of detergents complexed with membrane proteins. Sci. Rep. 7, 1-12. doi: 10.1038/srep41751

Dean, R., Van Kan, J. A. L., Pretorius, Z. A., Hammond-Kosack, K. E., Di Pietro, A., Spanu, P. D., et al. (2012). The top 10 fungal pathogens in molecular plant pathology. Mol. Plant Pathol. 13, 414-430. doi: 10.1111/j.13643703.2011.00783.x

Dobson, L., Reményi, I., and Tusnády, G. E. (2015). CCTOP: a consensus constrained TOPology prediction web server. Nucleic Acids Res. 43, W408-W412. doi: 10.1093/nar/gkv451

Doehlemann, G., Reissmann, S., Aßmann, D., Fleckenstein, M., and Kahmann, R. (2011). Two linked genes encoding a secreted effector and a membrane protein are essential for Ustilago maydis-induced tumour formation. Mol. Microbiol. 81, 751-766. doi: 10.1111/j.1365-2958.2011.07728.x

Fakhree, M. A. A., Blum, C., and Claessens, M. M. A. E. (2019). Shaping membranes with disordered proteins. Arch. Biochem. Biophys. 677:108163. doi: 10.1016/j.abb.2019.108163

Fisher, M. C., Henk, D. A., Briggs, C. J., Brownstein, J. S., Madoff, L. C., McCraw, S. L., et al. (2012). Emerging fungal threats to animal, plant and ecosystem health. Nature 484, 186-194. doi: 10.1038/nature10947

Fonseca-García, C., León-Ramírez, C. G., and Ruiz-Herrera, J. (2012). The regulation of different metabolic pathways through the $\mathrm{pal} / \mathrm{rim}$ pathway in Ustilago maydis. FEMS Yeast Res. 12, 547-556. doi: 10.1111/j.15671364.2012.00805.x

Giraldo, M. C., and Valent, B. (2013). Filamentous plant pathogen effectors in action. Nat. Rev. Microbiol. 11, 800-814. doi: 10.1038/nrmicro3119

Heigwer, F., Kerr, G., and Boutros, M. (2014). E-CRISP: fast CRISPR target site identification. Nat. Methods 11, 122-123. doi: 10.1038/nmeth.2812

Holliday, R. (1974). "Ustilago maydis," in Bacteria, Bacteriophages, and Fungi. ed. R. C. King (US: Springer), 575-595.

Huth, J. R., Bewley, C. A., Jackson, B. M., Hinnebusch, A. G., Marius Clore, G., and Gronenborn, A. M. (1997). Design of an expression system for detecting folded protein domains and mapping macromolecular interactions by NMR. Protein Sci. 6, 2359-2364. doi: 10.1002/pro.5560061109

Kämper, J., Kahmann, R., Bölker, M., Ma, L.-J., Brefort, T., Saville, B. J., et al. (2006). Insights from the genome of the biotrophic fungal plant pathogen Ustilago maydis. Nature 444, 97-101. doi: 10.1038/nature05248

Keon, J. P. R., White, G. A., and Hargreaves, J. A. (1991). Isolation, characterization and sequence of a gene conferring resistance to the systemic fungicide carboxin from the maize smut pathogen, Ustilago maydis. Curr. Genet. 19, 475-481. doi: 10.1007/BF00312739

Kijpornyongpan, T., Mondo, S. J., Barry, K., Sandor, L., Lee, J., Lipzen, A., et al. (2018). Broad genomic sampling reveals a smut pathogenic ancestry of the fungal clade Ustilaginomycotina. Mol. Biol. Evol. 35, 1840-1854. doi: 10.1093/molbev/msy072

Lanver, D., Müller, A. N., Happel, P., Schweizer, G., Haas, F. B., Franitza, M., et al. (2018). The biotrophic development of Ustilago maydis studied by RNA-Seq analysis. Plant Cell 30, 300-323. doi: 10.1105/tpc.17.00764

Lanver, D., Tollot, M., Schweizer, G., Presti, L. L., Reissmann, S., Ma, L.-S., et al. (2017). Ustilago maydis effectors and their impact on virulence. Nat. Rev. Microbiol. 15, 409-421. doi: 10.1038/nrmicro.2017.33
Lemoine, R., La Camera, S., Atanassova, R., Dédaldéchamp, F., Allario, T., Pourtau, N., et al. (2013). Source-to-sink transport of sugar and regulation by environmental factors. Front. Plant Sci. 4:272. doi: 10.3389/ fpls.2013.00272

Matei, A., Ernst, C., Günl, M., Thiele, B., Altmüller, J., Walbot, V., et al. (2018). How to make a tumour: cell type specific dissection of Ustilago maydisinduced tumour development in maize leaves. New Phytol. 217, 1681-1695. doi: $10.1111 / \mathrm{nph} .14960$

Morkunas, I., and Ratajczak, L. (2014). The role of sugar signaling in plant defense responses against fungal pathogens. Acta Physiol. Plant. 36, 1607-1619. doi: 10.1007/s11738-014-1559-Z

Mueller, O., Kahmann, R., Aguilar, G., Trejo-Aguilar, B., Wu, A., and de Vries, R. P. (2008). The Secretome of the maize pathogen Ustilago maydis. Fungal Genet. Biol. 45, S63-S70. doi: 10.1016/j.fgb.2008.03.012

Olerinyova, A., Sonn-Segev, A., Gault, J., Eichmann, C., Schimpf, J., Kopf, A. H., et al. (2021). Mass photometry of membrane proteins. Chem 7, 224-236. doi: 10.1016/j.chempr.2020.11.011

Roosild, T. P., Greenwald, J., Vega, M., Castronovo, S., Riek, R., and Choe, S. (2005). NMR structure of mistic, a membrane-integrating protein for membrane protein expression. Science 307, 1317-1321. doi: 10.1126/science.1106392

Sambrook, J., Fritsch, E. F., and Maniatis, T. (1989). Molecular Cloning: A Laboratory Manual. NY, USA: Cold Spring Harbor Laboratory.

Schuler, D., Wahl, R., Wippel, K., Vranes, M., Münsterkötter, M., Sauer, N., et al. (2015). Hxt1, a monosaccharide transporter and sensor required for virulence of the maize pathogen Ustilago maydis. New Phytol. 206, 1086-1100. doi: $10.1111 /$ nph.13314

Schuster, M., Schweizer, G., Reissmann, S., and Kahmann, R. (2016). Genome editing in Ustilago maydis using the CRISPR-Cas system. Fungal Genet. Biol. 89, 3-9. doi: 10.1016/j.fgb.2015.09.001

Schuster, M., Trippel, C., Happel, P., Lanver, D., Reißmann, S., and Kahmann, R. (2018). Single and multiplexed gene editing in Ustilago maydis using CRISPRCas9. Bio-Protocol 8, 1-15. doi: 10.21769/bioprotoc.2928

Selvig, K., and Alspaugh, J. A. (2011). PH response pathways in fungi: adapting to host-derived and environmental signals. Mycobiology 39, 249-256. doi: 10.5941/MYCO.2011.39.4.249

Soltermann, F., Foley, E. D. B., Pagnoni, V., Galpin, M., Benesch, J. L. P., Kukura, P., et al. (2020). Quantifying protein-protein interactions by molecular counting with mass photometry. Angew. Chem. Int. Ed. Eng. 59, 10774-10779. doi: 10.1002/anie.202001578

Sosso, D., van der Linde, K., Bezrutczyk, M., Schuler, D., Schneider, K., Kämper, J., et al. (2019). Sugar partitioning between Ustilago maydis and its host Zea mays L during infection. Plant Physiol. 179, 1373-1385. doi: 10.1104/ pp.18.01435

Tanaka, S., Brefort, T., Neidig, N., Djamei, A., Kahnt, J., Vermerris, W., et al. (2014). A secreted Ustilago maydis effector promotes virulence by targeting anthocyanin biosynthesis in maize. elife 3:e01355. doi: 10.7554/eLife.01355

Timmins, P. A., Leonhard, M., Weltzien, H. U., Wacker, T., and Welte, W. (1988). A physical characterization of some detergents of potential use for membrane protein crystallization. FEBS Lett. 238, 361-368. doi: 10.1016/00145793(88)80513-1

Uhse, S., Pflug, F. G., Stirnberg, A., Ehrlinger, K., von Haeseler, A., and Djamei, A. (2018). In vivo insertion pool sequencing identifies virulence factors in a complex fungal-host interaction. PLoS Biol. 16:e2005129. doi: 10.1371/journal.pbio.2005129

Van Der Lee, R., Buljan, M., Lang, B., Weatheritt, R. J., Daughdrill, G. W., Dunker, A. K., et al. (2014). Classification of intrinsically disordered regions and proteins. Chem. Rev. 114, 6589-6631. doi: 10.1021/cr400525m

Wahl, R., Wippel, K., Goos, S., Kämper, J., and Sauer, N. (2010). A nove high-affinity sucrose transporter is required for virulence of the plant pathogen Ustilago maydis. PLoS Biol. 8:e1000303. doi: 10.1371/journal.pbio.1000303

Zuo, W., Ökmen, B., Depotter, J. R. L., Ebert, M. K., Redkar, A., Villamil, J. M., et al. (2019). Molecular interactions between smut fungi and their host plants. Annu. Rev. Phytopathol. 57, 411-430. doi: 10.1146/annurevphyto-082718-100139

Conflict of Interest: The authors declare that the research was conducted in the absence of any commercial or financial relationships that could be construed as a potential conflict of interest. 
Copyright (c) 2021 Weiland and Altegoer. This is an open-access article distributed under the terms of the Creative Commons Attribution License (CC BY). The use, distribution or reproduction in other forums is permitted, provided the original author(s) and the copyright owner(s) are credited and that the original publication in this journal is cited, in accordance with accepted academic practice. No use, distribution or reproduction is permitted which does not comply with these terms. 